British Journal of Psychiatry (1992), 160, 861-872

\title{
Correspondence
}

Editor: Ian Pullen

Contents: Evolutionary genetic theory/Mentally handicapped epileptic patients: psychiatric illness and personality disorder/Ethical problems in genetic linkage studies/Western psychotherapy and nonWestern populations/Safety of 5-HT reuptake inhibitors/Serotonin, eating disorder, and HIV infection/Suicide prevention/Neuroleptic malignant syndrome/The naming of syndromes/Are nonWestern beliefs false?/Idiopathic genital pain and fluvoxamine/The 'Current Literature'-Worcester Development Project.

\section{Evolutionary genetic theory}

SIR: I have very much enjoyed reading Dr Crow's development of his genetic theory of psychosis, particularly as he is one of the few psychiatrists who understands the importance of adopting an evolutionary viewpoint (Journal, November 1991, 159 (suppl. 14), 76-82). Nevertheless, the theory appears to be fatally flawed as the basic concept of a 'psychosis gene' acting by arresting the development of Wernicke's area is incompatible with the findings of Suddath et al's (1990) monozygotic twin study, since the non-schizophrenic co-twins did not show ventricular enlargement. Reveley et al (1982) found the same pattern of change in ventricular size among their twins and both studies show that ventricular size is under a high degree of genetic control.

In the course of his article he places great emphasis on genetic diversity but then only considers variation in cerebral lateralisation. However, he refers to recently discovered neurophysiological mechanisms which have begun to elucidate non-verbal communication and aspects of paranoid behaviour. Now, if he were to consider the implications of variation in these mechanisms he would be on the threshold of embracing the genetic theory of psychosis I advanced some years ago (Farley, 1974 (unpublished), 1976).

Since my theory was published abroad and some time ago, many of your readers, possibly including Dr Crow, will not have seen it. Perhaps I may therefore outline the bare bones of it here.

A review of those forms of behaviour in which experimental studies up to that time had indicated a significant genetic component suggested that man possessed a whole repertoire of phylogenetic adaptations for group living. These included verbal and non-verbal communication, imitation, dominance and submission responses, obedience, acceptance of cultural values, protective phobic responses, orderliness, and various compulsions, guilt, self-criticism, group conformity, egoism, grandiosity, achievement need, distrust of strangers, and fear of being watched.

It was suggested that the innate mechanisms upon which each adaptation must depend were normally distributed in the population under polygenic control. Thus, most of a given population would be fairly evenly endowed with an average level of each mechanism and would tend to mature into average, well adjusted personalities. Some would inherit multiple deviations from the norm for that population and would tend to develop into unusual, unbalanced personalities. Their deficiency in coping behaviours could lead to over arousal and neurotic and affective reactions. Relatively minor stress could generate hyperarousal and release disintegrative psychoses, perhaps via cortical inhibition. However, among those with atypical genotypes, a few, especially the more intelligent, would emerge as highly creative individuals and become the agents of social change in the evolutionary process. In all cases, the quality of the environment experienced during maturation, including the pre-natal and physical environment, together with wholly learnt coping behaviours, would be the main determinants of outcome.

The diathesis I suggested for schizophrenia was a deficiency in verbal and non-verbal communication, including imitation; that for manic-depressive psychosis was an overloading with dominance and submission responses; and over-strong bonding and grief reactions for depressive psychosis.

A second strand of the theory saw psychotic manifestations as being these innate mechanisms displayed inappropriately and in incomplete, stereotyped forms. Since the characteristics of an individual's psychosis reflected the make-up of his genotype, the theory explained the familial occurrence of the different forms of psychosis. It also explained the typical manifestations of symptomatic psychoses 
and the relationship between psychosis, personality disorder and creativity.

A major stumbling block for the theory was the overlap it predicted between the diatheses for schizophrenia and high-functioning autism as at that time it was generally accepted that the two syndromes were unconnected. It is therefore most gratifying and opportune to read Dr Wolff's conclusion, also in the November issue, that schizoid disorders and autism are likely to be on a continuum (Journal, November 1991, 159, 621-625).

Finally, I would like to draw attention to a little known work by Henry Maudsley who appears to have been the first to see the significance of genetic diversity for psychiatry. I used the following passage as the introduction to an earlier unpublished manuscript (Farley, 1974).

"In the long run it is perhaps better for the species that there is here and there a family stock of such constitutional instability and tendency to variation, even though variation fated to go astray, than it would be for every stock to rest in the stable equilibrium of a set adaptation to its surroundings, bee-like in busy, or sheeplike in placid routine of automatic existence". (Henry Maudsley, 1908).

FArLeY, J. D. (1976) Phylogenetic adaptations and the genetics of psychosis. Acta Psychiatrica Scandinavica. 53, 173-192.

MAUdSLEY, H. (1908) Heredity. Variation and Genius. London: Bale \& Danielson.

Reveley, A. M., Reveley, M. A., Clufford, C. A., et al (1982) Cerebral ventricular size in twins discordant for schizophrenia. Lancet, i, 540-541.

Suddath, R. L., Christison, G. W., Torrey, E. F., et al (1990) Anatomical abnormalities in the brains of monozygotic twins discordant for schizophrenia. New England Journal of Medicine, 322, 789-794.

Bethcote Cottage

Holton

Oxford $O X 91 Q B$

JOHN D. FARLEY

AUTHOR'S REPLY: Dr Farley is correct in supposing that I had not read his 1976 paper. Now that I have done so I would like to draw attention to the logic of the first paragraph of that paper that I find persuasive:

"It is paradoxical that as the evidence for inherited factors in the aetiology of the functional psychoses becomes more complete, so theories as to the nature of what is genetically transmitted grow more indefinite. The high prevalence of functional psychosis, the distribution of cases, and evidence for some continuity between psychotic and normal behaviour, have all led to the increasing acceptance of polygenic theories at the expense of the heuristically more valuable monogenic theories. In the case of schizophrenia, the major proponents of the polygenic position suggest only that the genes predispose the subject specifically to develop this disease (Gottesman \&
Shields, 1972). No indication is given as to their function in the normal subject, who, by definition, also carries them. Bearing in mind, firstly, that the biological value of polygenes is to introduce graded variation into adaptations of survival value and, secondly, that the reproductive rate is reduced in overt schizophrenia, one would anticipate that these genes would also be responsible for transmitting something of considerable biological importance to man."

This seems to me to describe the nature of the problem succinctly, and to indicate the directions in which we should look for an answer. I would like to think that the polygenes to which Dr Farley refers constitute allelic variations at a single locus (as argued for example by Allen \& Sarich, 1988), and therefore will be more accessible to investigation than additive variation at a number of unrelated genetic loci, but there is as yet no strong evidence on this point.

Of additional interest is the emphasis that Farley (1976) places on the studies of Odegaard (1963) and Mitsuda (1967) on the genetics of psychosis. Neither of these authors adopts a Kraepelinian interpretation (i.e. the view that schizophrenia and manicdepressive psychosis are distinct entities) but rather construe their findings in terms of continuous variation. In this respect the findings, and Dr Farley's theory, are in line with the recent studies from Mainz (Maier \& Lichtermann, 1991) and with continuum concepts of psychosis (Crow, 1986, 1990b).

Dr Farley's contribution provokes the question of who first formulated an evolutionary theory of psychosis, and in what way do his and my own (Crow $1990 a, 1991)$ hypotheses relate to earlier concepts. I am aware of a number of hypotheses of this type, and am working on a review of this neglected field. I am grateful to Dr Farley for drawing my attention to aspects of which I was unaware.

Allen, J. S. \& SARICH, V. M. (1988) Schizophrenia in an evolutionary perspective. Perspectives in Biology and Medicine, 32, $132-153$.

Crow. T. J. (1986) The continuum of psychosis and its implication for the structure of the gene. British Journal of Psychiatry. 149, 419-429.

- $(1990 a)$ Temporal lobe asymmetries as the key to the aetiology of psychosis. Schizophrenia Bulletin, 16, 433-443.

- (1990b) The continuum of psychosis and its genetic origins. British Journal of Psychiatry, 156, 788-797.

- (1991) The origins of psychosis and 'The Descent of Man'. British Journal of Psychiatry. 159 (suppl. 14), 76-82.

T. J. Crow

Division of Psychiatry

Clinical Research Centre

Northwick Park Hospital

Harrow HAI 3 UJ

A full list of references is available from the author 